\title{
Research on the Impact of Technological Innovation on Environmental Pollution -- Based on the Moderating Effect of Internet Development
}

\author{
Jinghua $\mathrm{Wu}^{1, *}$ \\ ${ }^{1}$ School of Economics and Management, Beijing Jiaotong University, Haidian District, Beijing 100044, China
}

\begin{abstract}
Based on the provincial panel data from 2003 to 2015, this paper empirically investigates the impact of technological innovation on environmental pollution, and explores the moderating role of Internet development in this impact. It is found that technological innovation has a significant inhibitory effect on regional environmental pollution. The development level of the Internet has a significant regulating effect on the process of technological innovation affecting environmental pollution, which is manifested in that the improvement of the Internet development level can further enhance the inhibiting effect of technological innovation on environmental pollution and promote regional energy conservation and emission reduction. Based on the above analysis, this paper puts forward the corresponding countermeasures and suggestions.
\end{abstract}

\section{Introduction}

Since the reform and opening up, China's economy has achieved rapid development and made great achievements in economic construction. However, it is not negligible that China's extensive economic growth is more prominent, the environmental pollution is more serious. Take the industrial emissions in Fig.1 as an example, from 2003 to 2015, China's overall industrial emissions are on the rise. Although they have fluctuated and slowed in recent years, the total emissions are still large.

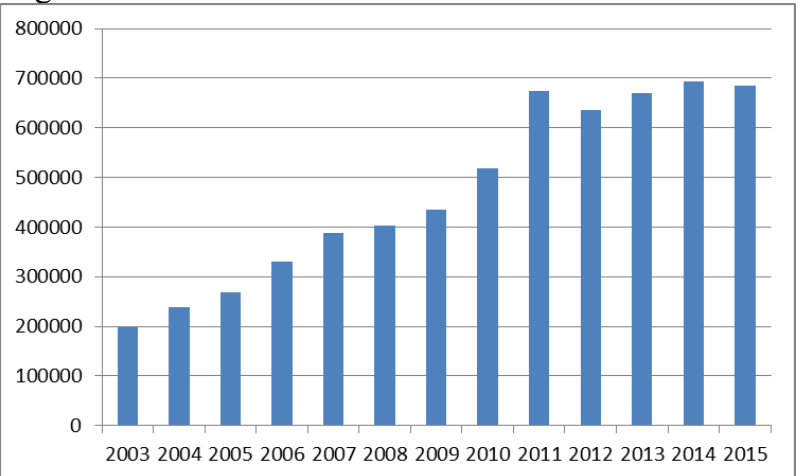

Fig. 1. China's industrial emissions from 2003 to 2015(100 million standard cubic meters).

Innovation drive is an important support and driving force for China's economic development. Technological innovation plays an increasingly important role in economic and industrial development. Then, will the improvement of China's technological innovation capacity contribute to the reduction of environmental pollution? At present, the new generation of information technology represented by the Internet is developing rapidly. Studies have shown that the development of the Internet will play a positive role in promoting regional innovation ability. So, will the development of the Internet affect the process of technological innovation affecting environmental pollution?

Based on the above analysis, this paper examines the impact of technological innovation on environmental pollution and adds the indicator of Internet development level to explore the moderating role of Internet development in the process of technological innovation affecting environmental pollution, so as to promoting China's technological innovation capacity and strengthening environmental protection.

\section{Literature review}

In the past, scholars have explored the factors influencing environmental pollution from many aspects, including urbanization, economic development, environmental regulation, foreign direct investment and industrial agglomeration. Kharel pointed out that urbanization will change the land use status and the original local ecosystem within a city, thus causing serious environmental pollution problems[1]. At the same time, during the process of urbanization, a large number of people gather in cities, and the increased energy demand in cities will also cause severe environmental pollution[2]. However, some scholars have pointed out that although urbanization intensifies the concentration of population and industrial activities in big cities, it can reduce the emission of industrial production, thus reducing environmental pollution[3]. The restraining effect of urbanization on environmental

\footnotetext{
* Corresponding author: 18120536@bjtu.edu.cn
} 
pollution may also be due to the fact that urbanization can improve the overall education level of a city and accelerate the accumulation of regional human capital, so as to provide high-quality human capital for the clean production of regional industries and more application of new technologies and equipment[4].

As for the relationship between enterprise innovation and environmental pollution, many scholars believe that scientific and technological innovation or technological progress can reduce environmental pollution and promote energy conservation and emission reduction. He Xiaogang and Zhang Yaohui pointed out that industrial technological progress can significantly promote energy conservation and emission reduction[5]. Li Bo found through empirical research that regional carbon emission level decreased with the improvement of regional innovation capacity[6]. Zhou Jieqi and Wang Tongsan divided patents into three types in their empirical research, and concluded that no matter which type of patent can significantly reduce carbon emissions[7].

Varian believed that the development of information technology changed the traditional transaction mode and could promote enterprise innovation in many aspects[8]. The impact of Internet development on regional innovation efficiency was not only heterogeneous between different regions, but also varied with different innovation subjects, such as enterprises, universities and scientific research institutions[9].

It can be seen from the above analysis that previous studies on environmental pollution and regional innovation focused on discussing technological innovation and environmental pollution, Internet development and innovation, etc., while no scholars have yet linked regional Internet development level with environmental pollution. On the basis of studying the impact of technological innovation on environmental pollution, this paper investigates the moderating role of Internet development in the process of technological innovation on environmental pollution. It is of great guiding significance to make full use of Internet resources, promote the improvement of regional innovation capacity and reduce environmental pollution.

\section{Model setting and variable selection}

\subsection{Model setting}

In order to explore the impact of technological innovation on environmental pollution and the moderating effect of Internet development, the following regression models are set in this paper:

$$
\ln P O_{\mathrm{it}}=\beta_{0}+\beta_{1} \ln T E_{\mathrm{it}}+\beta_{2} X_{\mathrm{it}}+\mu_{\mathrm{i}}+\delta_{\mathrm{t}}+\varepsilon_{\mathrm{it}}
$$

$\ln P O_{\mathrm{it}}=\beta_{0}+\beta_{1} \ln T E_{\mathrm{it}}+\beta_{2} \ln T E_{\mathrm{it}} * \ln I N T_{\mathrm{it}}+\beta_{3} X_{\mathrm{it}}+\mu_{\mathrm{i}}+\delta_{\mathrm{t}}+\varepsilon_{\mathrm{it}}$

Formula (1) is used to explore the impact of technological innovation on environmental pollution, while formula (2) is used to explore the moderating role of Internet development in the process of technological innovation affecting environmental pollution.
Among them, i represents the province, $t$ represents the time, $P O_{\text {it }}$ represents the environmental pollution, $T E_{\text {it }}$ represents the technology innovation ability, $I N T_{\text {it }}$ represents the Internet development, $X_{\text {it }}$ represents the control variables that may affect environmental pollution, $\mu_{\mathrm{i}}$ represents provinces does not change with time of invisible factors, $\delta_{\mathrm{t}}$ is used to control the time fixed effects, $\varepsilon_{\text {it }}$ as random perturbation terms. All the variables are logarithmic.

\subsection{Variable selection}

The explained variable in this paper is environmental pollution (PO). In this paper, the total amount of industrial sulfur dioxide emissions is selected as a representative of the environmental pollution. The explanatory variable of this paper is technological innovation (TE). Drawing on previous studies by scholars, this paper selects the number of patent application authorization to represent technological innovation. The moderating variable in this paper is the Internet development level (INT), and the Internet penetration rate is selected as the proxy variable.

In addition, the following control variables are included. Investment in environmental pollution control (INV): the total investment in environmental pollution control in each region is selected as the proxy index of environmental pollution control investment. Energy consumption (ENE): in this paper, energy consumption in various regions is selected as the proxy index. Economic development level (AGDP): in this paper, the per capita GDP of each region is selected as the proxy indicator of economic development level. Considering that economic development may have a non-linear impact on environmental pollution, the quadratic term of economic development level (AGDP2) is added. Foreign direct investment (FDI): this paper selects the actual utilization of foreign direct investment in each region as the proxy index of foreign direct investment.

\subsection{Data sources}

This paper selects the data of 30 provinces, municipalities and autonomous regions in China from 2003 to 2015. Due to the lack of data in Tibet, Hong Kong, Macao and Taiwan, the above four regions are excluded in this paper. The data used in this paper are from China science and technology statistical yearbook, China statistical yearbook and statistical yearbooks of various regions from 2004 to 2016.

\section{Results and analysis}

Before the regression analysis, Hausmann Test is first used to test the above model. The results shows that this paper is suitable for the fixed-effect model, and the specific regression results are shown in Table 1. 
Table 1. Impacts of technological innovation and Internet development on environmental pollution.

\begin{tabular}{|c|c|c|}
\hline & \multicolumn{2}{|c|}{ Explained variables: $\ln \mathrm{PO}$} \\
\hline $\begin{array}{c}\text { Explanatory } \\
\text { variables }\end{array}$ & (1) & (2) \\
\hline $\ln T E$ & $\begin{array}{c}-0.2234 * * * \\
(-6.87)\end{array}$ & $\begin{array}{c}-0.159 * * * \\
(-3.96)\end{array}$ \\
\hline $\ln T E^{*} \ln I N T$ & & $\begin{array}{c}-0.0117 * * * \\
(-2.69)\end{array}$ \\
\hline $\ln I N V$ & $\begin{array}{l}0.0158 \\
(0.48)\end{array}$ & $\begin{array}{l}0.0223 \\
(0.68)\end{array}$ \\
\hline $\ln E N E$ & $\begin{array}{l}0.6534^{* * * *} \\
(6.84)\end{array}$ & $\begin{array}{c}0.7067 * * * \\
(7.31)\end{array}$ \\
\hline $\ln A G D P$ & $\begin{array}{c}3.1213 * * * \\
\quad(5.25)\end{array}$ & $\begin{array}{c}2.9749 * * * \\
\quad(5.03)\end{array}$ \\
\hline $\operatorname{LnAGDP2}$ & $\begin{array}{c}-0.1652 * * * \\
(-5.28)\end{array}$ & $\begin{array}{c}-0.1531 * * * \\
(-4.88)\end{array}$ \\
\hline $\operatorname{lnFDI}$ & $\begin{array}{l}0.0164 \\
(0.71)\end{array}$ & $\begin{array}{l}0.0265 \\
(1.14)\end{array}$ \\
\hline$C$ & $\begin{array}{l}-5.84 * * \\
(-2.03)\end{array}$ & $\begin{array}{c}-6.2719^{* *} \\
(-2.19)\end{array}$ \\
\hline$R^{2}$ & 0.68 & 0.77 \\
\hline Model & FE & FE \\
\hline
\end{tabular}

$5 \%$ and $1 \%$ respectively.

According to model 1, the impact of technological innovation on environmental pollution is significantly negative, indicating that with the improvement of regional innovation capacity, regional environmental pollution level will decrease. In other words, technological innovation can significantly inhibit environmental pollution and promote energy conservation and emission reduction.

Model 2 is the regression result after adding the interaction term of technological innovation and Internet development level. The impact of technological innovation on environmental pollution is still significantly negative, and the interaction term of technological innovation and Internet development level is also significantly negative, indicating that the improvement of regional Internet development level will further strengthen the inhibitory effect of technological innovation on environmental pollution. The possible reason lies in that the improvement of Internet development level can provide a better Internet environment for enterprises within the region, accelerate the popularization and application of new achievements and new technologies, which is conducive to improving the innovation efficiency and management level of research and development subjects, so as to strengthen the role of technological innovation in promoting energy conservation and emission reduction.
From the results of the control variables, the impact of the investment in environmental pollution control is positive but not significant, indicating that the current investment in environmental pollution control in China has not been fully utilized and cannot play a role in promoting energy conservation and emission reduction. The coefficient of energy consumption is significantly positive, indicating that the increase in energy consumption will aggravate regional environmental pollution. This is mainly because China's energy structure is still dominated by coal and other disposable energy sources, which has a large negative impact on the environment. The primary term of GDP per capita is positive, while the secondary term is negative, indicating that economic development is positively correlated with environmental pollution at a low level of economic development. When economic development reaches a certain level, the improvement of economic development can reduce environmental pollution, mainly because people pay more attention to environmental protection at this time. The effect of FDI is positive but not significant, indicating that the increase of FDI is not the main cause of the worsening of environmental pollution in China.

\section{Conclusion}

Based on the provincial panel data from 2003 to 2015, this paper studies the relationship between technological innovation and environmental pollution, and considers the moderating effect of Internet development level. The study finds that technological innovation significantly curbes China's environmental pollution; the development level of the Internet can enhance the inhibitory effect of technological innovation on environmental pollution and promote energy conservation and emission reduction. The increase of energy consumption and the improvement of economic development level will aggravate the regional environmental pollution.

Accordingly, this paper puts forward the following countermeasures and suggestions. (1) Each region should formulate policies to promote technological innovation according to its own economic development reality, guide regional innovation activities reasonably, and give full play to its promoting role in energy conservation and emission reduction. (2) Regional technological innovation and Internet layout should be combined to complement and improve each other, and coordination and interaction between the two should be played to better promote regional energy conservation and emission reduction.

\section{References}

1. Kharel, G.Impacts of Urbanization on Environmental Resources:A Land Use Planning Perspectivee[D].Arlington:University of Texas, 2010.

2. He Xiaoping, Liu Xiying, Lin Yanping. China's Electricity Demand Forecast under Urbanization Process[J]. Economic Research Journal, 2009, (1) :118-130. 
3. Lu Ming, Feng Hao. Agglomeration and emission reduction: empirical study on the influence of city size gap on industrial pollution intensity $[\mathrm{J}]$. The Journal of World Economy, 2014, (7) :86-114.

4. Zhang Tengfei, Yang Jun, Sheng Pengfei. The Impacts and Channels of Urbanization on Carbon Dioxide Emissions in China [J]. China Population, Resources and Environment, 2016, (2) :47-57.

5. He Xiaogang, Zhang Yaohui. Technology Progress, Energy Save and Emission Reduce and Development Pattern Transformation [J]. The Journal of Quantitative \& Technical Economics,2012(3):19-33.

6. Li bo. District Technological Innovation Capacity and Carbon Emission Per Capita of China-An Empirical Analysis Based on Spatial Econometric Model of Provincial Panel Data [J]. Soft Science,2013(1):26-30.

7. Zhou Jieqi, Wang Tongsan. Effect on the China Carbon Emissions of Independent Technology Innovation-An Empirical Study Based Provincial Panel Data [J]. Science \& Technology Progress and Policy,2014(24):29-35.

8. Varian, h. r. computer-mediated Transactions[J]. American Economic Review, 2010,100(2):1-10.

9. Han Xianfeng, Song Wenfei, Li Boxin. Can the Internet Become a New Momentum to Improve the Efficiency of Regional Innovation in China [J]. China Industrial Economics,2019(7):119-136. 